\title{
A RBO na era da informação digital
}

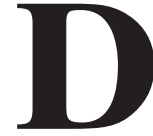

urante os últimos anos, a Revista Brasileira de Oftalmologia (RBO) sofreu importantes modificações na sua forma de divulgação. Uma modificação marcante foi passar a integrar os periódicos da Biblioteca Científica Eletrônica em linha, SciELO ( em inglês, Scientific Eletronic Library on line). Esta biblioteca eletrônica abrange uma coleção selecionada de periódicos ibero-americanos, que são disponibilizados integralmente e de forma gratuita pela internet.

A partir do momento que os artigos da RBO puderam ser acessados pela web, seu poder informativo ficou maior e também se tornou possível medir o número de acessos aos artigos em determinado espaço de tempo.

Alguns colegas afirmam que as revistas nacionais são pouco lidas e que os artigos devem ser publicados para terem boa visibilidade em publicações internacionais. No entanto, observa-se no Portal SciELO desde fevereiro de 2008 (quando começou a estatística) que os artigos da RBO digitalizados apresentaram até 2010, 221.900 (duzentos e vinte e um mil e novecentos) acessos.

Os acessos a artigos de fevereiro a dezembro de 2008 foram 24.270 (vinte e quatro mil, duzentos e setenta), enquanto que de fevereiro a dezembro de 2010 foram de 105.723 (cento de cinco mil, setecentos e vinte e três). Portanto, em três anos os acessos quintuplicaram.

Embora tais números sejam expressivos, em comparação com outras publicações nacionais, eles poderiam aumentar significativamente. Por exemplo: a Revista Clinics da USP apresentou de fevereiro de 2008 a 2010 um total de 1.224.156 (um milhão, duzentos e vinte e quatro mil, cento e cinquenta e seis) acessos a seus artigos, ou seja, aproximadamente cinco vezes mais do que os da RBO. Uma característica que diferencia esta Revista da RBO é que seus artigos são publicados predominantemente em inglês.

Outro dado relevante a ser considerado em uma revista científica é o número de citações de seus artigos por outras publicações. De acordo com a SciELO, a RBO possuía até 2010, um total de 808 citações recebidas por outras publicações científicas, sendo que o periódico que mais citou a RBO foi o Arquivos Brasileiros de Oftalmologia. Na lista de periódicos que citaram a Revista constam também publicações de outras áreas médicas como o Jornal de Pediatria, Revista Brasileira de Dermatologia ou de Otorrinolaringologia, Revista de Saúde Pública etc. No entanto, há poucas publicações internacionais, como os Archivos da Sociedad Espanola de Oftalmologia ou o International Journal of Morphology. Receber e conceder citações para outros periódicos nacionais contribui para o desenvolvimento da ciência em nosso país. Contudo, os números indicam uma maior necessidade de internacionalização da RBO.

A língua inglesa é considerada língua franca da ciência atualmente. $\mathrm{O}$ acesso ao aprendizado do idioma inglês é o maior e o mais fácil entre os diversos idiomas. A proficiência em inglês é considerada pré-requisito para inúmeros programas de pós-graduação stricto sensu. O idioma em que a maioria de artigos, ou seus resumos, são escritos no mundo é o inglês. Portanto, a publicação em inglês dá maior visibilidade internacional a um determinado artigo científico.

Em vários países, o desenvolvimento da habilidade de escrever em inglês faz parte do currículo acadêmico, como na Universidade de Michigan ou Universidade de Toronto. Na América do Sul, pro- 
gramas acadêmicos para aperfeiçoar a escrita em inglês de textos científicos são raros. No Brasil, um grande número de escolas de idiomas ensina Inglês para o cotidiano, negócios ou viagens. Ensinar como escrever a pesquisa científica em inglês não faz parte do currículo da maioria das universidades Brasileiras. Portanto, é importante para os Brasileiros que desejam publicar seus trabalhos em inglês e não dominam a linguagem acadêmica escrita desta língua utilizar os serviços de revisores ou tradutores. O site www.journalexperts.com é exemplo de serviços de revisão e tradução.

Todas as estatísticas citadas neste texto foram divulgadas no site da SciELO-Brasil (www.scielo.br) com data de processamento de 15/12/2010.

Como membro do Corpo Editorial da RBO nos últimos seis anos, aceitei com satisfação o convite para ser o Editor da Revista no biênio de 2011 e 2012. Facilitar a publicação dos artigos científicos da RBO em inglês, trabalhar para permitir a indexação da Revista em bases como o Medline, e procurar continuamente aumentar a citação de seus artigos por outras publicações e consequentemente o seu fator de impacto, são metas para os próximos dois anos.

Arlindo José Freire Portes

Professor Adjunto de Oftalmologia da Universidade Estácio de Sá-RJ Editor-Chefe da Revista Brasileira de Oftalmologia 